\title{
Adrenal Steroids Modulate Fibroblast-Like Synoviocytes Response During B. abortus Infection
}

\author{
María Virginia Gentilini, Guillermo Hernán Giambartolomei and María Victoria Delpino* \\ Instituto de Inmunología, Genética y Metabolismo (INIGEM), Universidad de Buenos Aires (UBA), Consejo Nacional de \\ Investigaciones Cientificas y Técnicas (CONICET), Buenos Aires, Argentina
}

OPEN ACCESS

Edited by:

Vinicius Frias Carvalho, Oswaldo Cruz Foundation

(Fiocruz), Brazil

Reviewed by:

Cristiana Couto Garcia,

Oswaldo Cruz Foundation

(Fiocruz), Brazil

Patrícia Paiva Corsetti,

University of José de Rosário

Vellano, Brazi

Huynh Tan Hop,

Gyeongsang National University,

South Korea

*Correspondence:

María Victoria Delpino mdelpino@ffyb.uba.ar

Specialty section:

This article was submitted to

Neuroendocrine Science,

a section of the journal

Frontiers in Endocrinology

Received: 11 July 2019 Accepted: 07 October 2019

Published: 22 October 2019

Citation:

Gentilini MV, Giambartolomei GH and

Delpino MV (2019) Adrenal Steroids Modulate Fibroblast-Like Synoviocytes Response During B. abortus Infection.

Front. Endocrinol. 10:722

doi: 10.3389/fendo.2019.00722
Brucella abortus stimulates an inflammatory immune response that stimulates the endocrine system, inducing the secretion of dehydroepiandrosterone (DHEA) and cortisol. In humans, the active disease is generally present as osteoarticular brucellosis. In previous studies we showed that $B$. abortus infection of synoviocytes creates a proinflammatory microenvironment. We proposed to determine the role of cortisol and DHEA on synoviocytes and infiltrating monocytes during $B$. abortus infection. Cortisol inhibited IL-6, IL-8, MCP-1, and MMP-2 secretion induced by $B$. abortus infection in synovial fibroblast. Cortisol-mediated MMP-2 inhibition during B. abortus infection was reversed by IL-6. DHEA inhibited $B$. abortus-induced RANKL up-regulation in synovial fibroblast through estrogen receptor (ER). B. abortus infection did not modulate glucocorticoid receptor (GR) expression. Cell responses to cortisol also depended on its intracellular bioavailability, according to the activity of the isoenzymes $11 \beta$-hydroxysteroid dehydrogenase (HSD) type-1 and 11 -HSD2 (which are involved in cortisone-cortisol interconversion). B. abortus infection did not modify $11 \beta-H S D 1$ expression and $\mathrm{GR} \alpha / \beta$ ratio in the presence or absence of adrenal steroids. Supernatants from $B$. abortus-infected monocytes induced $11 \beta$-HSD1 in synovial cells. Administration of cortisone was capable of inhibiting the secretion of RANKL by synoviocytes mimicking cortisol's effect. These results go along with previous observations that highlighted the ability of synovial tissue to secrete active steroids, making it an intracrine tissue. This is the first study that contributes to the knowledge of the consequence of adrenal steroids on synoviocytes in the context of a bacterial infection.

Keywords: DHEA, cortisol, Brucella, synovial fibroblast (FLS), RANKL

\section{INTRODUCTION}

Brucellosis is an infection caused by bacteria of the genus Brucella. This is one of the infectious diseases transmissible between animals and humans. Brucella osteoarthritis is one of the most common features of human brucellosis. The most frequent joint involvements are spondylitis, arthritis, and osteomyelitis $(1,2)$. The acute and the chronic forms of human brucellosis present joint involvement. Clinical characteristics include joint pain, which increased local warmth, tenderness, and limitation of movement. In brucellar arthritis, cartilage loss, and bone erosion affecting different joints may eventually lead to permanent joint dysfunction $(3,4)$. In about $50 \%$ of the cases of osteoarciular brucellosis, bacteria are isolated from synovial fluid samples. In the affected joint, the synovial membrane may present a lymphomononuclear infiltrate in the chronic phase of the disease, but usually this takes place in the acute setting $(5,6)$. 
Synovial damage caused by Brucella infection involves different immune mechanisms. We have demonstrated that Brucella infects and survives within human synoviocytes, and this infection elicits a proinflammatory microenvironment with the secretion of interleukin (IL)-6 and the chemokines IL-8; chemoattractant of neutrophils and monocyte chemoattractant protein 1 (MCP-1); chemoattractant of monocytes; and the secretion of matrix metalloproteases (MMPs) and RANKL-with concomitant osteoclastogenesis $(7,8)$.

During Brucella infection different cytokines generated, including those produced in the local osteoarticular site, exerted a direct effect on immune or bone cells and also influenced indirectly these cells through their capacity to influence several neuroendocrine mechanisms, including the stimulation of the hypothalamus-pituitary-adrenal axis (HPA) (9). A cross-regulation between adrenal steroids (glucocorticoids and dehydroepiandrosterone [DHEA]) and the immune response modulation (10) has been established. The effects of DHEA are frequently opposed by the adrenal steroid cortisol (11). Further, in the course of immune response, hormones are endogenously released. The type of immune response that humans develop against Brucella infection is influenced by glucocorticoids and DHEA. Accordingly, it has been demonstrated that in patients with acute brucellosis, cortisol levels were more elevated than those of healthy individuals $(12,13)$. In addition, we have previously demonstrated that steroid hormones are implicated in the modulation of osteoblast differentiation and macrophage response during $B$. abortus infection $(13,14)$. In synoviocytes, the link between inflammation and the endocrine system at local level may be due to the presence of functional receptors for glucocorticoids, androgens, and estrogens.

The potential mechanism that is involved in synoviocytes and bone damage during Brucella infection has been partially deciphered $(7,8)$. Considering our previous results which demonstrate an inappropriate secretion of steroid hormones in patients with acute brucellosis $(12,13)$, the aim of this work was to determine if this hormonal dysregulation is implicated in the development and evolution of osteoarticular disease.

To this end we investigated the consequence of cortisol and DHEA on synoviocyte responses during B. abortus infection.

\section{METHODS}

\section{Bacterial Culture}

Brucella abortus S2308 was grown overnight in $10 \mathrm{ml}$ of tryptic soy broth (Merck, Buenos Aires, Argentina) with constant agitation at $37^{\circ} \mathrm{C}$. To prepare the bacteria inocula, we performed the procedure previously described (14). All live Brucella manipulations were carried out in biosafety level 3 facilities located at the at the Instituto de Investigaciones Biomédicas en Retrovirus y SIDA (INBIRS).

\section{Cell Culture}

The immortalized human FLS cell line SW982 was obtained from the ATCC (Rockville, MD). The SW982 cell line was cultured in an $\alpha$-Minimum Essential Medium ( $\alpha$-MEM) (Gibco) supplemented with $2 \mathrm{mM}$ L-glutamine, $10 \%$ heat-inactivated fetal bovine serum (FBS) (Gibco), $100 \mathrm{U} / \mathrm{ml}$ penicillin, and $100 \mu \mathrm{g} / \mathrm{ml}$ streptomycin. The human monocytic cell line THP1 was cultured in RPMI 1640 medium (Gibco) supplemented with $2 \mathrm{mM} \mathrm{L}$-glutamine, $10 \%$ heat inactivated FBS, $100 \mathrm{U} / \mathrm{ml}$ penicillin, and $100 \mu \mathrm{g} / \mathrm{ml}$. The cultures were maintained in a $5 \%$ $\mathrm{CO} 2$ atmosphere at $37^{\circ} \mathrm{C}$.

\section{Cellular Infection}

SW982 at a concentration of $3 \times 10^{5}$ cells/well (for cytokine determination by ELISA) and at $5 \times 10^{4}$ cells/well (for intracellular survival assay) were seeded in 24-well plates, and at $5.2 \times 10^{5}$ cells/well (for mRNA extraction) it was seeded in 6well plates. It was infected at different multiplicities of infection (MOI) in the presence or absence of DHEA $\left(1 \times 10^{-8} \mathrm{M}\right)$ and cortisol $\left(1 \times 10^{-6} \mathrm{M}\right)$ and incubated for $1 \mathrm{~h}$ at $37^{\circ} \mathrm{C}$ in a $5 \% \mathrm{CO}_{2}$ atmosphere. Cells were extensively washed with DMEM-F12 to remove extracellular bacteria and were incubated in medium supplemented with $100 \mu \mathrm{g} / \mathrm{ml}$ of gentamicin and $50 \mu \mathrm{g} / \mathrm{ml}$ of streptomycin to kill extracellular bacteria in the presence or absence of DHEA and cortisol at the indicated concentrations. SW982 cells and culture supernatants were harvested at $24 \mathrm{~h}$ to obtain whole cell extracts and determine cytokines, chemokine production, matrix metalloproteinase (MMP) secretion, and mRNA extractions. To determine Brucella intracellular survival, cells were lysed with a sterile solution of $0.1 \%$ (vol/vol) Triton $\mathrm{X}-100$ in $\mathrm{H}_{2} \mathrm{O}$. To enumerate $\mathrm{CFU}$, lysates from serial dilutions were plated on tryptic soy agar plates.

THP-1 cells were seeded at $5 \times 10^{5}$ cells/well in 24-well plates and infected at MOI 100 for $1 \mathrm{~h}$, then washed with RPMI and incubated during $24 \mathrm{~h}$ with medium supplemented with antibiotics as was described above.

Neutralization experiments were performed with anti-TNF receptor (anti-TNFRc, BD biosciences) at a concentration of $20 \mu \mathrm{g} / \mathrm{ml}$. Synoviocytes were preincubated with the anti-TNFRc neutralizing antibody $(20 \mathrm{mg} / \mathrm{ml})$ or its corresponding isotype controls for $1 \mathrm{~h}$ at $37^{\circ} \mathrm{C}$, and then stimulated with supernatants from $B$. abortus-infected monocytes.

Fulvestrant treatment was performed by using a concentration of $10 \mu \mathrm{M}$ of Fulvestrant (Sigma).

\section{Measurement of Cytokine Concentrations}

Secretion of IL-6, TNF- $\alpha$, IL-1 $\beta$, IL-10, IL-8, and monocyte chemotactic protein 1 (MCP-1) was quantified by enzymelinked immunosorbent assay (ELISA; BD Biosciences, San Jose, CA) and RANKL was quantified by ELISA (R\&D systems) in culture supernatants.

\section{Zymography}

The method of Hibbs et al. with modifications was used to determine gelatinase activity $(7,15)$. The reversion of the inhibitory effect of cortisol on MMP production was carried out in the presence of human recombinant IL-6 at a concentration of $20 \mathrm{ng} / \mathrm{ml}$ (rhIL-6, R\&D Systems).

\section{mRNA Preparation and Quantitative PCR}

RNA was extracted using the Quick-RNA MiniPrepKit (Zymo Research) and $1 \mu \mathrm{g}$ of RNA was subjected to reverse transcription 
using Improm-II Reverse Transcriptase (Promega). PCR analysis was performed with a Mx3000P real-time PCR detection system (Stratagene) using SYBR Green as fluorescent DNA binding dye. The primer sets used for amplification were: CycA sense: $5^{\prime}$ GCATACGGGTCCTGGCATCTTG-3', antisense: $5^{\prime}$ - TGCC ATCCAACCACTCAGTCTTG-3'; $11 \beta$-HSD1 sense $5^{\prime}$ - ATGA TATTCACCATGTGCGCA-3' antisense $5^{\prime}$ - ATAGGCAG CAACCATTGGATAAG-3'; $11 \beta$-HSD2 sense $5^{\prime}$ - TCGCGCGG TGCTCATCAC-3'antisense 5' - GTACGCAGCTCGATGGCA CC $-3^{\prime} ;$ GR $\alpha$ sense $5^{\prime}$ - GAAGGAAACTCCAGCCAGAAC-3' antisense $5^{\prime}$ - GATGATTTCAGCTAACATCTCG-3'; GR $\beta$ sense 5'- GAAGGAAACTCCAGCCAGAAC-3'antisense $5^{\prime}$ - TGAG CGCCAAGATTGTTGG-3'; DKK1 sense $5^{\prime}$ - TCCCCTGT GATTGCAGTAAA-3' antisense 5'- TCCAAGAGATCCTTGC GTTC-3'.

The amplification cycle for $\mathrm{GR} \alpha$ and $\mathrm{GR} \beta$ was $95^{\circ} \mathrm{C}$ for $15 \mathrm{~s}, 65^{\circ} \mathrm{C}$ for $30 \mathrm{~s}$ and $72^{\circ} \mathrm{C}$ for $60 \mathrm{~s}$ while for $11 \beta$-HSD 1 and DKK1 it was $95^{\circ} \mathrm{C}$ for $15 \mathrm{~s}, 62,5^{\circ} \mathrm{C}$ for $30 \mathrm{~s}$ and $72^{\circ} \mathrm{C}$ for $60 \mathrm{~s}$. The fold change (relative expression) in gene expression was calculated using the relative quantitation method $\left(2^{-\Delta \Delta \mathrm{Ct}}\right)$. Relative expression levels were normalized against CycA.

\section{Statistical Analysis}

Statistical analysis was performed with one-way analysis of variance, followed by the post-hoc Tukey test, using GraphPad Prism 5.0 software. The data are represented as means \pm standard error of the mean (SEM).

\section{RESULTS}

\section{Cortisol and DHEA Modulate B. abortus Intracellular Replication in Synovial Cells}

We have previously demonstrated that primary human synovial fibroblast and SW982 cell line support B. abortus invasion and replication $(7,8)$. Taking into account that adrenal steroids do not only alter the function of host cells but can also affect the intracellular replication of bacteria $(13,16,17)$, we aimed to determine if these hormones could modify $B$. abortus replication in synovial fibroblast. The capacity of $B$. abortus to replicate in synovial fibroblast was significantly increased by cortisol with respect to untreated controls. In contrast, DHEA treatment had no effect. However, during the administration of cortisol and DHEA in conjunction, no differences were observed in intracellular bacterial survival with respect to untreated cells, indicating that DHEA avoided the effect of cortisol These differences were significant at 24,48 , and $72 \mathrm{~h}$ postinfection (Figures 1A,B). Taken together, these results indicate the intracellular replication of Brucella was increased by cortisol treatment whereas DHEA treatment avoided this effect.

\section{Cortisol Inhibits IL-6, IL-8, and MCP-1 Induced by $B$. abortus Infection in Synovial Fibroblast}

B. abortus-infected synovial fibroblasts secrete the proinflammatory cytokine IL-6, chemokines, and MMP-2, but not the anti-inflammatory cytokine IL-10 (data not shown).
In the migration of innate inflammatory cells, chemokines, and MMPs participated (18) in the concomitant tissue damage. Adrenal steroids can modulate the expression of cytokines, chemokines and MMPs in several cell types. When synovial fibroblasts were infected with $B$. abortus in the presence of cortisol, these cells secreted significantly lower quantities of IL-6, IL-8, MCP-1, and MMP-2 in respect to untreated cells. DHEA treatment could not avoid the effect of cortisol on IL-6, IL-8, and MCP-1 expression but could partially avoid the inhibitory effect of cortisol on MMP-2 expression, as was demonstrated when infection experiments were performed in the presence of both cortisol and DHEA (Figures 1B-E). Our results show that cortisol reduces the expression of secreted mediators induced by $B$. abortus infection in synoviocytes and DHEA could only partially avoid the effect in MMP-2 expression.

\section{IL-6 Avoids the Effect of Cortisol Inhibition of MMP-2 Secretion Induced by $B$. abortus Infection in Synovial Fibroblast}

Proinflammatory cytokines have been previously implicated in MMP induction in different cell types (19-24). The role of IL6 in the downmodulation of MMP-2 induced by cortisol in $B$. abortus-infected synovial fibroblast was determined by adding recombinant human IL- 6 exogenously at the time of treatment. IL-6 was able to avoid the inhibitory effect on MMP-2 secretion induced by cortisol in B. abortus-infected synovial fibroblasts (Figure 1F). This indicates that cortisol downmodulated MMP2 secretion in a mechanism that at least involved the dampening of IL-6 production.

\section{DHEA Inhibits $B$. abortus-Induced RANKL Up-Regulation in Synovial Fibroblast Through Estrogen Receptor (ER)}

RANKL is the master regulator of bone metabolism involved in osteoclast differentiation (cell type implicated in bone resorption) in physiological conditions. In pathological conditions, the increase of RANKL expression could induce an exacerbation of bone resorption. We have previously demonstrated that $B$. abortus infection induced an increase of RANKL expression in synoviocytes. Then, experiments were conducted to determine if adrenal steroids could modulate RANKL expression during B. abortus infection in synoviocytes. To this end, infection experiments were performed in the presence of cortisol and DHEA. Cortisol treatment significantly reduced the secretion of RANKL with respect to untreated cells. In addition, DHEA treatment could also partially inhibit RANKL secretion induced by B. abortus infection (Figure 2A). These results indicate that adrenal hormones reduced the expression of RANKL induced by B. abortus infection in synoviocytes.

Infiltrating monocytes could be infected by $B$. abortus and then secrete proinflammatory cytokines and a low amount of IL-10 in response to this infection (Figure 2C) (25-27). This in turn could modulate synovial fibroblast responses $(7,27)$. Thus, we aimed to determine if supernatants from $B$. abortusinfected monocytes could modulate RANKL expression and if this response could be modified by the presence of adrenal 


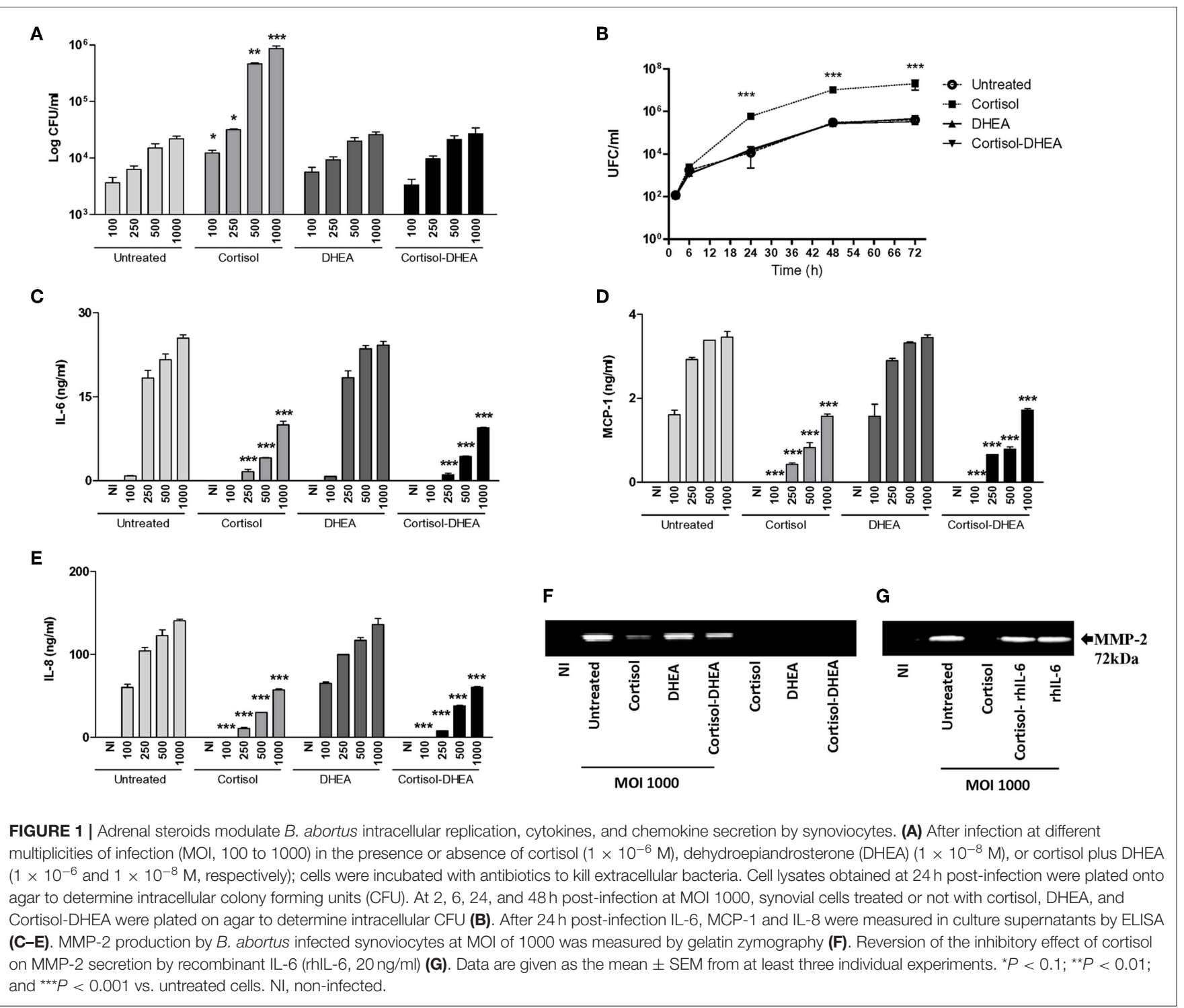

steroids. Our results indicate that supernatants from B. abortusinfected monocytes induce RANKL expression by synoviocytes. When stimulation experiments were performed in the presence of cortisol, the expression of RANKL was completely abrogated. DHEA was able to reduce the levels of the expression of RANKL induced by supernatants from $B$. abortus-infected monocytes (Figure 2B). These results indicate that RANKL expression induced by supernatants from $B$. abortus-infected monocytes was inhibited by cortisol and DHEA treatment.

Most of the action of DHEA is mediated through ER (28). Then, experiments were conducted to evaluate the role of ER in the inhibition of the effect of $B$. abortus infection or supernatants from $B$. abortus-infected monocytes on RANKL expression in synoviocytes. To this end, fulvestran-mediated ER inhibition was employed to investigate the role of ER in regulating the DHEA effect on RANKL expression in synoviocytes infected with $B$. abortus or stimulated with conditioned medium. Fulvestrant was able to avoid the effect of DHEA in the inhibition of RANKL in $B$. abortus-infected synoviocytes or when stimulated with supernatants from $B$. abortus-infected synoviocytes (Figures 2A,B). Therefore, these results indicate that DHEA modulates the secretion of RANKL by synoviocytes mainly through ER.

\section{B. ABORTUS INFECTION INDUCES DICKKOPF-1 (DKK1) EXPRESSION IN SYNOVIOCYTES}

A main factor involved in the regulation of bone biology is DKK1 , and it is deemed a contributing factor in bone resorption (29). Since DKK-1 is produced by synoviocytes, experiments were conducted to determine if $B$. abortus infection could induce DKK-1 expression and the ability of adrenal steroids to modulate this response. B. abortus infection induced DKK-1 expression with respect to uninfected cells (Figure 3A). Cortisol 


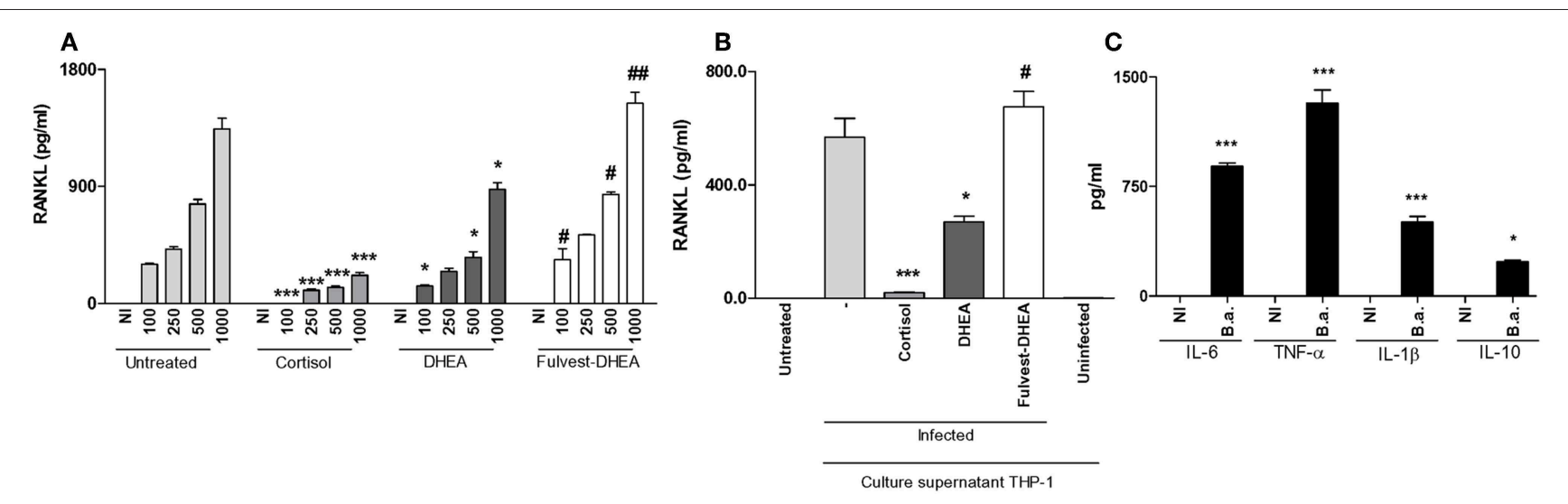

FIGURE 2 | DHEA inhibits RANKL induced by B. abortus infection and culture supernatants from B. abortus-infected monocytes via estrogen receptor (ER). Synoviocytes were infected at different $\mathrm{MOI}$ or stimulated with $1 / 2$ dilution of culture supernatants from $B$. abortus infected or uninfected THP-1 cells, in the presence or not of cortisol $\left(1 \times 10^{-6} \mathrm{M}\right)$, dehydroepiandrosterone $(\mathrm{DHEA})\left(1 \times 10^{-8} \mathrm{M}\right)$, and in the presence or not of the ER inhibitor, fulvestrant $(\mathrm{Fulvest}$, $10 \mu \mathrm{M})$. RANKL was measured by ELISA in culture supernatants from $B$. abortus-infected synoviocytes (A) or in culture supernatants from synoviocytes stimulated with culture supernatants from $B$. abortus infected THP-1 cells (culture supernatants THP-1, infected) or culture supernatants from uninfected THP-1 cells (culture supernatants THP-1, uninfected) (B). IL-6, TNF- $\alpha, I L-1 \beta$, and IL-10 levels were determined in culture supernatants from $B$. abortus-infected THP-1 cells (C). Data are given as the mean \pm SEM from at least three individual experiments. ${ }^{\star} P<0.1$ and ${ }^{\star \star \star} P<0.001$ vs. untreated cells. $\# P<0.05$ and $\# \# P<0.01$ vs. DHEA treated cells. NI, non-infected.

and DHEA had no effect on the expression of DKK-1 in B. abortus-infected cells at least at $24 \mathrm{~h}$ (Figure 3A). It has been previously shown that inflammatory mediators can induce the expression of DKK-1. B. abortus-infected macrophages secrete proinflammatory cytokines (25-27). Thus, we decided to investigate if supernatants from $B$. abortus-infected monocytes could induce DKK-1 expression by synoviocytes. Supernatants from $B$. abortus-infected monocytes failed to induce DKK1 expression as was determined at $24 \mathrm{~h}$ post-stimulation. Cortisol and DHEA had no effect on this response (Figure 3B). Taken together, our results indicated that B. abortus-infected synoviocytes express DKK-1 that could contribute to bone damage and B. abortus- infected monocytes did not contribute to DKK-1 expression at the mentioned time of stimulation. In addition, in these conditions, cortisol and DHEA did not participate in the modulation of DKK-1.

\section{B. abortus Infection Does Not Modulate Cortisol Intracellular Bioavailability in Synovial Fibroblasts}

The capacity of cells to respond to cortisol depends not only on levels of circulating cortisol, but it is also dependent on GR expression and its intracellular bioavailability. This depends on the activity of the isoenzymes $11 \beta$-hydroxysteroiddehydrogenase type 1 (11 $\beta$-HSD1) and type $2(11 \beta$-HSD2) that catalyze the interconversion of inactive cortisol (cortisone) to active cortisol and vice versa, respectively. Thus, experiments were conducted to establish if $B$. abortus infection could modulate the two GR receptor isoforms, termed GR $\alpha$ and GR $\beta$; as well as $11 \beta$-HSD1 and $11 \beta$-HSD2 expression and to establish if this phenomenon could be modulated by adrenal steroid treatment during the infection. $B$. abortus infection did not induce the expression of GR $\alpha, \mathrm{GR} \beta$, and $11 \beta$-HSD1, with respect to uninfected cells (Figure 4). In addition, adrenal steroids were unable to modulate the expression of GR $\alpha, \mathrm{GR} \beta$, and $11 \beta$-HSD1 during $B$. abortus infection. In concordance of previous reports, $11 \beta$-HSD2 was not detectable in synovial fibroblast (30). These results indicated that $B$. abortus infection did not modulate GR and $11 \beta$-HSD1 in synoviocytes.

\section{Adrenal Steroids Modulate 11 $\beta$-HSD1, $\mathrm{GR} \alpha$, and GR $\beta$ Expression in $B$. abortus-Infected Monocytes}

Brucella-infected synovial fibroblasts have the ability to secrete MCP-1, a key cytokine involved in monocyte migration, and monocytes could be attracted to the site of infection and contribute to modulate synovial responses. Experiments were then performed to determine if $B$. abortus infection could modulate $11 \beta$-HSD1, $11 \beta$-HSD2, GR $\alpha$, and GR $\beta$ expression in THP-1 monocytes. B. abortus infection did not induce $11 \beta$-HSD1 expression in monocytes (Figure 5A). Infection experiments in the presence of cortisol or DHEA indicated that both steroids were able to reduce $11 \beta$-HSD1 expression. In accordance with previous results by others, the type 2 enzyme, $11 \beta$-HSD2, which converts cortisol to cortisone, was not detectable in monocytes (31).

B. abortus infection was also able to induce GR $\alpha$ and GR $\beta$ expression in monocytes. When infection experiments were performed in the presence of adrenal steroids, our results indicate that cortisol had no significant effect on GR $\alpha$ and GR $\beta$ expression. In contrast, DHEA was able to reduce GR $\alpha$ and GR $\beta$ up to basal levels (Figures 5B,C). When we analyze the GR $\alpha / \beta$ ratio, our results demonstrate that $B$. abortus infection induced a reduction of $\mathrm{GR} \alpha / \beta$ ratio, the treatment with cortisol had no effect, and the infection experiments in the presence of DHEA increased the $G R \alpha / \beta$ ratio up to basal levels present in uninfected cells (Figure 5D). 


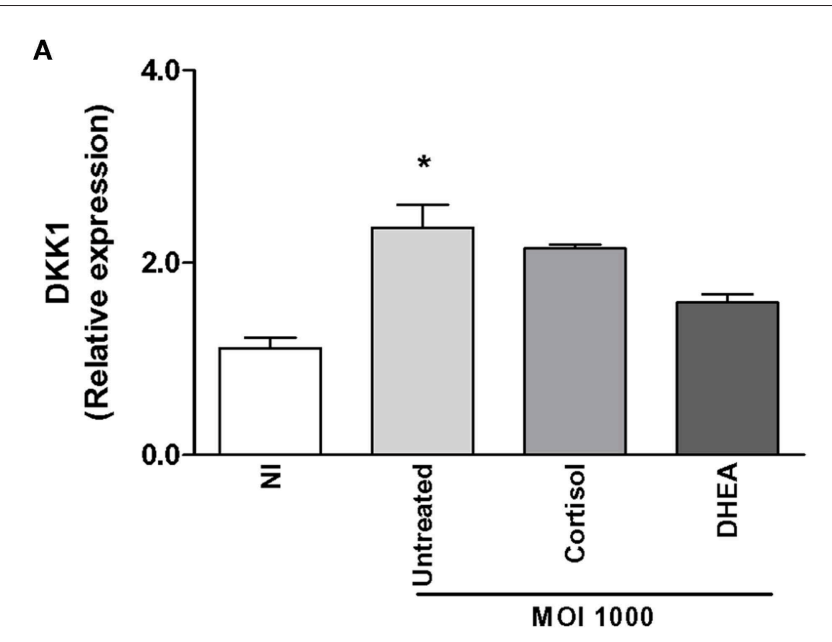

B

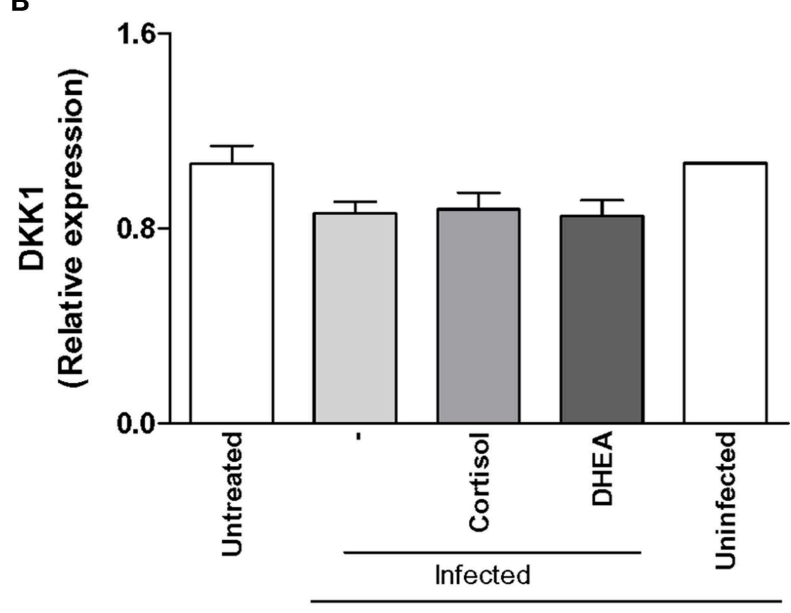

Culture supernatant THP-1

FIGURE 3 | Effect of $B$. abortus infection and culture supernatants from $B$. abortus-infected monocytes on dickkopf-1 (DKK1) expression in synoviocytes. DKK1 expression was determined by RT-qPCR in synoviocytes infected by $B$. abortus at a MOI of 1000 or stimulated with $1 / 2$ dilution of culture supernatants from $B$. abortus-infected or uninfected THP-1 cells, in the presence or not of cortisol $\left(1 \times 10^{-6} \mathrm{M}\right)$ and dehydroepiandrosterone (DHEA) $\left(1 \times 10^{-8} \mathrm{M}\right)$ for $24 \mathrm{~h}$. Data are given as the mean \pm SEM from at least three individual experiments. ${ }^{\star} P<0.1$ vs. untreated infected cells. NI, non-infected.

Together, our results indicate that B. abortus infection did not increase the ability of the cells to respond to cortisol since it did not significantly increase $11 \beta$-HSD1 expression or the $\mathrm{GR} \alpha / \beta$ ratio.

\section{Supernatants From B. abortus-Infected Monocytes Modulate GR and 11 $\beta$-HSD1 Expression in Synoviocytes}

As was mentioned before, infiltrating monocytes could be infected by B. abortus and secrete proinflammatory cytokines in response to this infection that could modulate synovial fibroblasts responses. Thus, we aimed to determine if supernatants from
B. abortus-infected monocytes could modulate GR $\alpha$, GR $\beta$, and $11 \beta$-HSD1 expression in synovial fibroblasts.

Supernatants from B. abortus-infected monocytes induced an increase of $11 \beta$-HSD1 with respect to cells stimulated with supernatants from uninfected monocytes. Cortisol significantly increased the induction in $11 \beta$-HSD 1 mRNA transcription induced by supernatants from $B$. abortus-infected monocytes; in contrast, DHEA had no effect (Figure 6A). When we analyzed the modulation of supernatants from $B$. abortusinfected monocytes on the expression of GR in synoviocytes, our results indicate that supernatants from $B$. abortus-infected monocytes did not modulate GR $\alpha$ expression in synovial fibroblasts (Figure 6B). In addition, when stimulation with $B$. abortus-infected monocytes was performed in the presence of cortisol and DHEA, our results indicated that cortisol and DHEA had no effect. When we analyzed the expression of GR $\beta$, supernatants from $B$. abortus-infected monocytes induced GR $\beta$ expression (Figure 6C). The presence of cortisol was able to inhibit the stimulatory effect of supernatants from $B$. abortus-infected monocytes on GR $\beta$ expression. In contrast, the presence of DHEA had no effect. It is well-known that GR $\beta$ lacks the capacity to bind glucocorticoids, and it seems to act as an inhibitor of GR $\alpha$-mediated transcriptional activation through the formation of GR $\alpha / G R \beta$ heterodimers (32). In this context, stimulation with supernatants from B. abortus-infected monocytes did not have a significant effect on $\mathrm{GR} \alpha / \beta$ ratio, and the treatment with cortisol or DHEA had no effect (Figure 6D).

\section{Supernatants From B. abortus-Infected Monocytes Induce 11 $\beta$-HSD1 Expression Through TNF- $\alpha$}

TNF- $\alpha$ is abundant in sites of osteoarticular inflammation (33). At the local level it has been described that TNF- $\alpha$ modulates $11 \beta$-HSD1 in order to convert cortisone in their active form cortisol (34).

Then, we asked if the increment of $11 \beta$-HSD1 transcription observed in synoviocytes treated with supernatants from $B$. abortus-infected monocytes was mediated by TNF- $\alpha$. To this end, stimulation of synoviocytes with supernatants from $B$. abortus-infected monocytes was performed in the presence of an anti-TNFRc-blocking antibody. TNFRc-blocking antibody significantly inhibits the expression of $11 \beta$-HSD1, whereas an isotype control had no effect (Figure 7A). These results indicated that TNF- $\alpha$ secreted by $B$. abortus-infected monocytes could be involved in the induction of $11 \beta$-HSD1.

\section{Cortisone Fails to Enhance 11 $\beta$-HSD1 but Inhibits RANKL Induced by Supernatants From B. abortus-Infected Monocytes}

We demonstrated that supernatants from B. abortus-infected monocytes induce $11 \beta$-HSD1 expression, and this expression is increased when stimulation was performed in the presence of cortisol. Thus, we decided to determine the effect of added cortisone instead of cortisol with culture supernatants from $B$. abortus-infected monocytes on $11 \beta$-HSD1 expression in synoviocytes. To this end, stimulation experiments were 

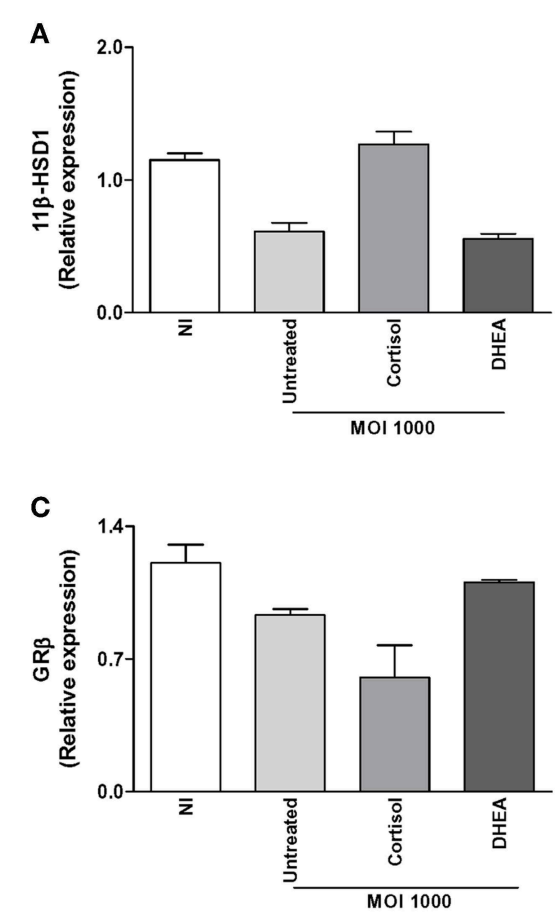

B

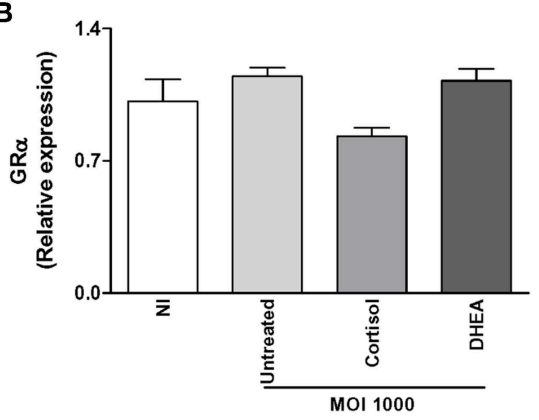

D

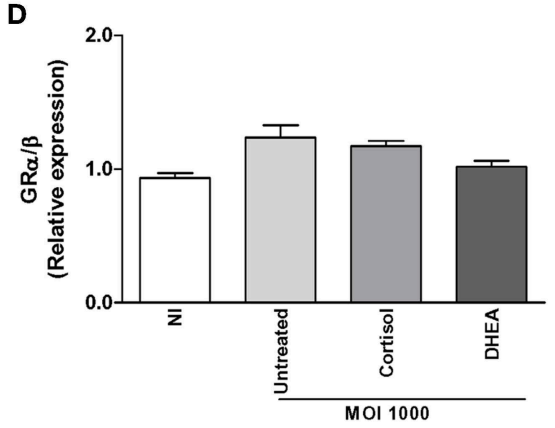

FIGURE 4 | Adrenal steroids do not modulate glucocorticoid receptor (GR) and 11 $\beta$-hydroxysteroid dehydrogenase (HSD)-1 during B. abortus infection. 11 $\beta$-HSD1, $\mathrm{GR} \alpha$, and GR $\beta$ expression were determined by RT-qPCR in B. abortus-infected synoviocytes at MOl of 1000 in the presence or not of cortisol $\left(1 \times 10^{-6} \mathrm{M}\right)$ and dehydroepiandrosterone $(\mathrm{DHEA})\left(1 \times 10^{-8} \mathrm{M}\right)$ for $24 \mathrm{~h} .11 \beta-\mathrm{HSD} 1$ (A), GR $\alpha$ (B), GR $\beta$ (C), GR $\alpha / \beta$ ratio (D). Data are given as means $\pm \mathrm{SEM}$ from at least three individual experiments. NI, non-infected.

performed by added culture supernatants from B. abortusinfected monocytes, and after $24 \mathrm{~h}$ of stimulation they were treated with cortisone or cortisol as a control. After $24 \mathrm{~h}$, cells were harvested to determine the expression of $11 \beta$ HSD1. Addition of cortisone to cells stimulated with culture supernatants from $B$. abortus-infected monocytes had no effect on $11 \beta$-HSD1 expression with respect to cells stimulated with supernatants from $B$. abortus-infected monocytes alone (Figure 7B). However, cortisone inhibits RANKL secretion induced by supernatants from $B$. abortus-infected monocytes (Figure 7C). These results indicate that although supernatants from $B$. abortus-infected monocytes were able to induce $11 \beta$ HSD1, cortisone was unable to enhance the expression of $11 \beta$ HSD1 but mimicked the effect of cortisol on the modulation of RANKL expression.

\section{DISCUSSION}

The immune system does not respond in isolation. The immune system along with the endocrine axis and the neural system act together to fight diseases. Adrenal glands secrete cortisol, a glucocorticoid hormone that plays a role in the stress response, and DHEA that has frequently opposing actions to cortisol (35).

Although the role of adrenal steroids on synovial cells has been previously studied, the impact in the context of bacterial infection has not been elucidated until now. In this context, in brucellosis, it has been previously shown that this infection elicits an imbalance in the cortisol/DHEA ratio that could impact the immune response $(12,13)$. Our results indicated that in synoviocytes, cortisol treatment increased $B$. abortus intracellular proliferation. This phenomenon was avoided when both cortisol and DHEA were administrated in conjunction. This increase in bacterial load has been previously described during intracellular infection of other bacteria-Salmonella typhimurium, Mycobacterium tuberculosis, and inclusive $B$. abortus $(13,14,16,17)$. However, the mechanisms involved in the increase of intracellular growth were not completely elucidated. While some hormones induce and increase in bacteria virulence factor expression in Mycoplasma hyopneumoniae, Vibrio parahaemolyticus, and Candida albicans (36-38), cortisol was unable to induce an increase of virulence factors in Salmonella typhymurium (16).

Accordingly, with its opposite effect with respect to cortisol, DHEA treatment avoided the effect of cortisol, as was revealed in cells treated with cortisol and DHEA in conjunction. On the other hand, cortisol was able to promote B. abortus infection not only through its intracellular replication but also by the inhibition of the immune response and cell function in synoviocytes (39). In agreement with other observations, cortisol suppressed proinflammatory mediator secretion by B. abortusinfected synoviocytes, and DHEA was able to partially avoid this effect at least for MMP-2. These results again support the antagonist effect of DHEA (11). The role of proinflammatory 

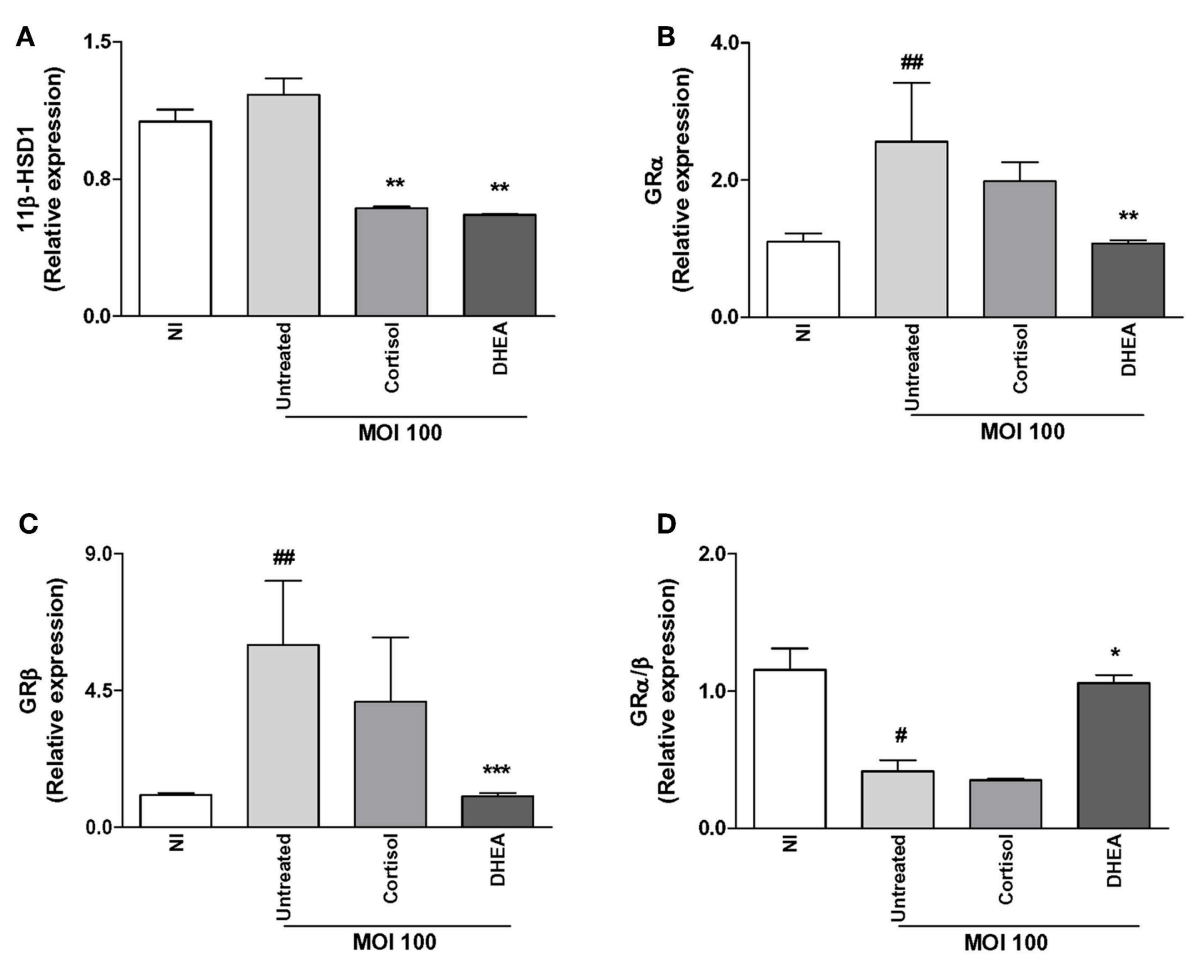

FIGURE 5 | Effect of adrenal steroids on glucocorticoid receptor (GR) and 11 $\beta$-hydroxysteroid dehydrogenase (HSD)-1 expression in $B$. abortus-infected monocytes. $11 \beta$-HSD1, GR $\alpha$, and GR $\beta$ expression were determined by RT-qPCR in B. abortus-infected THP-1 cells at MOl of 100 in the presence or not of cortisol $\left(1 \times 10^{-6} \mathrm{M}\right)$, dehydroepiandrosterone (DHEA) $\left(1 \times 10^{-8} \mathrm{M}\right)$ for $24 \mathrm{~h} .11 \beta-\mathrm{HSD} 1$ (A), GR $\alpha$ (B), GR $\beta$ (C), GR $\alpha / \beta$ ratio (D). Data are given as the mean $\pm \mathrm{SEM}$ from at least three individual experiments. ${ }^{*} P<0.1$; ${ }^{\star \star} P<0.01$; and ${ }^{* \star *} P<0.001$ vs. untreated cells: $\# P<0.1$; and $\# \# P<0.01$ vs. untreated infected cells. Nl, non-infected.

cytokines on MMP induction has been extensively reported in osteoarticular diseases (19-24). B. abortus infection induces IL6 but not TNF- $\alpha$ and IL-1 $\beta$ production by synovial cells. Since rhIL-6 was able to reverse the inhibitory effect of cortisol on MMP-2 secretion in B. abortus-infected synovial cells, it suggests that IL-6 could be involved in such induction.

In osteoarthritis, osteoclast formation is enhanced by proinflammatory cytokines from infiltrating immune cells but also synoviocytes enhance osteoclast formation via expression of RANKL (40). During osteoarticular brucellosis, the expression of RANKL could be increased by $B$. abortus infection and by the proinflammatory environment created by $B$. abortusinfected monocytes. In this context, DHEA was able to inhibit RANKL expression. The role of DHEA in the modulation of RANKL expression was described in the context of inflammatory non-infectious osteoarticular disease $(41,42)$. In addition, DHEA mediated this effect through ER receptor as evidenced when infections and the treatment with supernatants from $B$. abortus-infected monocytes were performed in the presence of fulvestrant. The ability of DHEA and its metabolites to signal through androgen receptor (AR) and ER has been previously described $(43,44)$. However, since the addition of ER antagonist, fulvestrant, completely avoids the effect of DHEA on RANKL expression, we could affirm that the main signaling of DHEA during $B$. abortus infection in sinoviocytes is via ER.
The presence of functional ER in synoviocytes might link the endocrine system and inflammation at the local level (45). The ability of DHEA to regulate RANKL through ER has been demonstrated previously at least in osteoblast cells (44). This indicated that ER could play a role in the modulation of osteoclastogénesis through the modulation of the key molecule implicated in osteoclastogenesis, RANKL in B. abortusinfected synoviocytes.

DKK-1 is the master regulator of bone remodeling in osteoarticular inflammatory disease (46). DKK-1 expression inhibits osteoblast differentiation and increases osteoclastogenesis with concomitant bone resorption. $B$. abortus induces the increase of DKK-1 expression in synoviocytes; this is in concordance with the bone resorption observed in patients with osteoarticular brucellosis. However, supernatants from $B$. abortus-infected monocytes were unable to induce DKK-1 expression. This could be explained, at least in part, by the role of TNF- $\alpha$, IL- 6 , and IL- $1 \beta$ present in culture supernatants from B. abortus-infected monocytes on DKK-1 expression. While TNF- $\alpha$ suppresses bone formation by inducing DKK-1, IL-6, and IL-1 $\beta$ have been reported as inhibitors of DKK-1 expression $(47,48)$. Then, the cytokines combined in the culture supernatants from $B$. abortus-infected monocytes were unable to induce DKK-1 expression. 

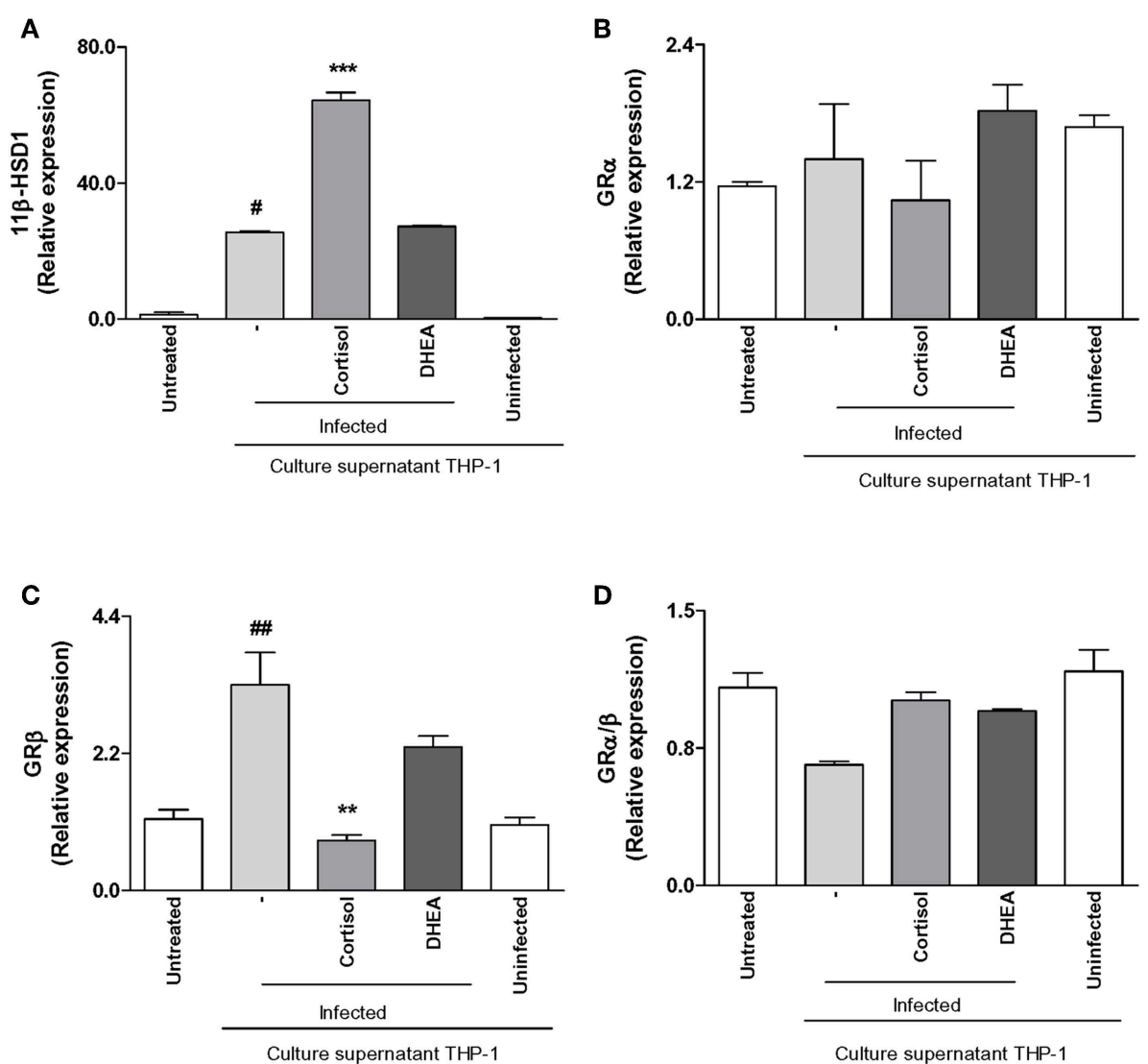

FIGURE 6 | Adrenal steroids modulate 11ß-hydroxysteroid dehydrogenase (HSD)-1 and glucocorticoid receptor (GR) in synoviocytes stimulated with culture supernatants from B. abortus-infected monocytes. 11 $\beta$-HSD1, GR $\alpha$, and GR $\beta$ expression were determined by RT-qPCR in synoviocytes stimulated with $1 / 2$ dilution of culture supernatants from $B$. abortus infected or uninfected THP-1 cells, in the presence or not of cortisol $\left(1 \times 10^{-6} \mathrm{M}\right)$ and dehydroepiandrosterone (DHEA) $(1 \times$ $10^{-8}$ M) for $24 \mathrm{~h}$. $11 \beta-H S D 1$ (A), GR $\alpha$ (B), GR $\beta$ (C), GR $\alpha / \beta$ ratio (D). Data are given as means \pm SEM from at least three individual experiments. ${ }^{* *} P<0.01$, and ${ }^{\star \star *} P$ $<0.001$ vs. absence of cortisol. $\# P<0.1$; and \#\#P<0.01 vs. non-infected culture supernatant THP-1.
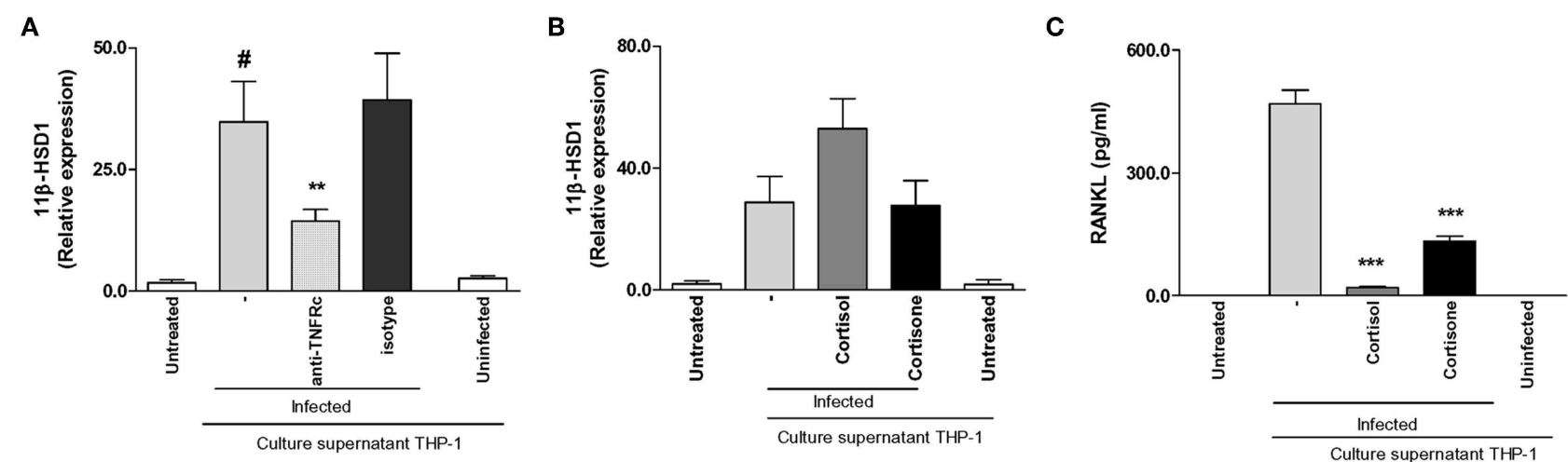

FIGURE 7 | Supernatants from B. abortus-infected monocytes induce 11 1 -hydroxysteroid dehydrogenase (HSD)-1 expression in a mechanism that is dependent on the presence of TNF- $\alpha$. Synoviocytes were stimulated with $1 / 2$ dilution of culture supernatants from $B$. abortus infected or uninfected THP-1 cells in the presence or not of cortisol $\left(1 \times 10^{-6} \mathrm{M}\right)$, or cortisone $\left(1 \times 10^{-6} \mathrm{M}\right)$ in the presence or not of anti-TNF receptor neutralizing antibody (anti-TNFRc) at a concentration of $20 \mu \mathrm{g} / \mathrm{ml}$ for $24 \mathrm{~h}$; and 11 $\beta$-HSD1 expression was determined by RT-qPCR (A,B). RANKL was determined in culture supernatants by ELISA (C). Data are given as means \pm SEM from at least three individual experiments. ${ }^{\star} P<0.1$, vs. anti-TNFRc. ${ }^{\star \star \star} P<0.001$ vs. cortisol and cortisone treatment. ${ }^{\#} P<0.1$ vs. non-infected culture supernatant THP-1. NI, non-infected. 


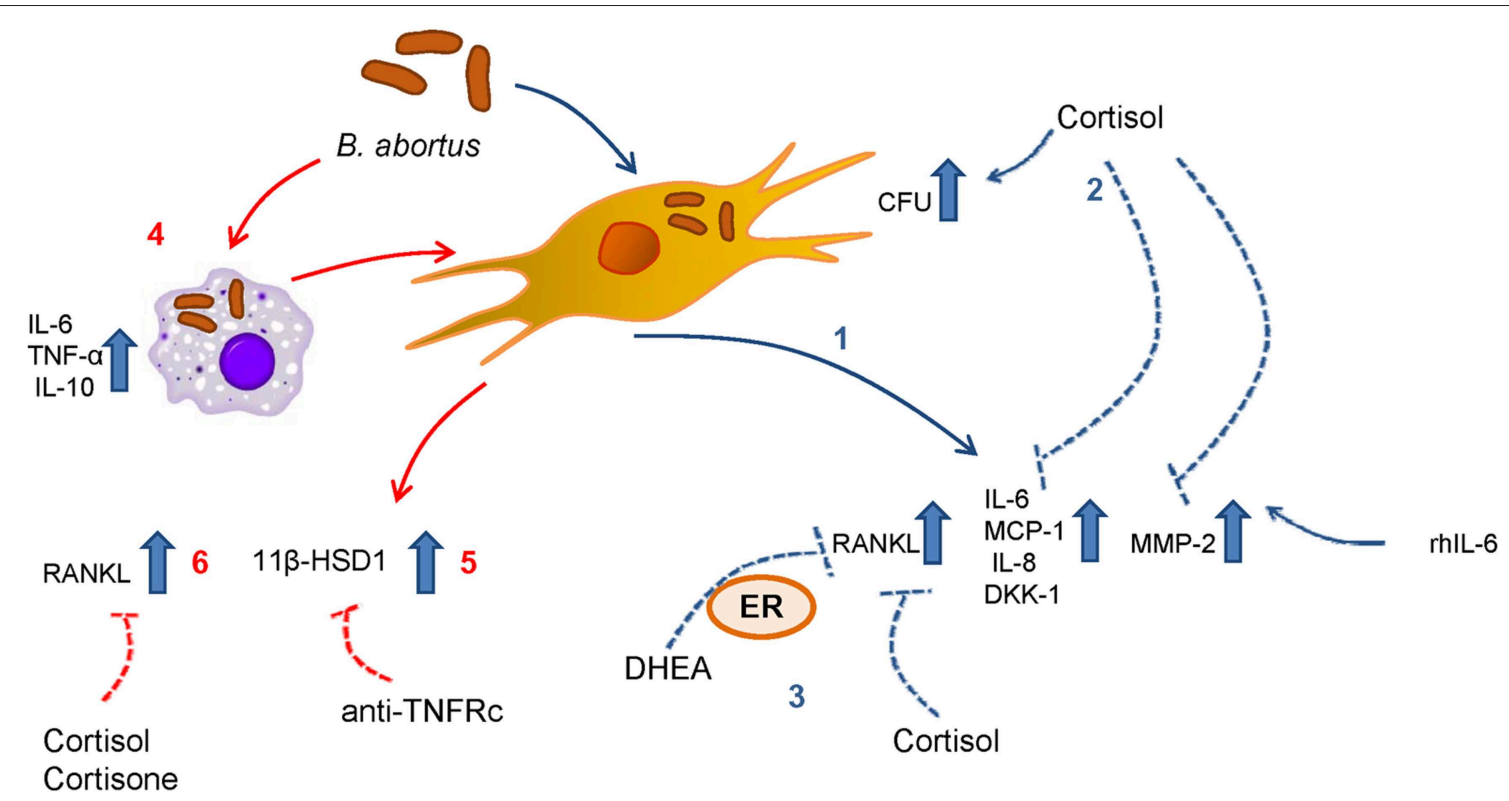

FIGURE 8 | Scheme summarized the results for the mechanisms involved in the modulation of synoviocytes by adrenal steroids during $B$. abortus infection. (1) Infection with B. abortus induces the secretion of RANKL, IL-6, MCP-1, IL-8, DKK-1, and MMP-2. (2) When cortisol is present, the intracellular CFU is increased with respect to untreated cells. (3) DHEA and cortisol avoid the increase of RANKL induced by $B$. abortus infection. The action of DHEA is mediated through the ER. (4) $B$. abortus infection induces the secretion of IL-6, TNF- $\alpha$, and IL-10 by monocytes. (5) Supernatants from B. abortus-infected monocytes induce $11 \beta$-HSD1 in a mechanism that is dependent on TNFRc. (6) In addition, supernatants from B. abortus-infected monocytes induce RANKL, cortisol, and cortisone avoid this effect.

The effect of cortisol in synovial cells does not dependent on an increase of their bioavailability, as was demonstrated by the non-modification of $11 \beta$-HSD1 and GR $\alpha / \beta$ ratio in response to $B$. abortus infection in the presence or absence of adrenal steroids. A similar situation was found for B. abortus-infected monocytes in which $B$. abortus infection had no effect on $11 \beta$ HSD1 but cortisol and DHEA treatment inhibited its expression in the context of the infection. In addition, $B$. abortus infection in the presence or not of cortisol inhibited GR $\alpha / \beta$ ratio and DHEA could avoid this effect. In synoviocytes and monocytes, the absence of detectable expression of $11 \beta$-HSD2 deserves to be discussed since this enzyme is involved in the conversion of cortisol in its inactive form, cortisone. The absence of negligible levels of 11ß-HSD2 in human monocytes, macrophages and dendritic cells has been reported $(31,49)$. In synovial cells, a high expression of $11 \beta-\mathrm{HSD} 1$ has been demonstrated, mainly in synovial fibroblast, whereas $11 \beta-\mathrm{HSD} 2$ is primarily restricted to synovial macrophages (30). Taking into account that we evaluated the effect of $B$. abortus infection in synovial fibroblast, our findings are in line with previous results.

Although the ability of monocytes to induce proinflammatory cytokines in response to $B$. abortus infection has been widely demonstrated $(25,27)$, supernatants from B. abortus-infected monocytes appear to have some anti-inflammatory effect, as was revealed by the induction of $11 \beta-H S D 1$ in synovial cells. Despite this, cortisone does not seem to increase the expression of $11 \beta$-HSD1 as it does cortisol. However, the administration of cortisone is capable of inhibiting the secretion of RANKL by synoviocytes mimicking the cortisol effect. This indicates the importance of the increase of $11 \beta-H S D 1$ in the utilization of cortisone. This is in accordance with previous observations that highlight the ability of synovial tissue to make active steroids, and this tissue has been considered an intracrine tissue (45). The increase of $11 \beta$-HSD1 expression induced by cortisol in synoviocytes treated with culture supernatants from B. abortus-infected monocytes also deserves to be discussed. The interactions between proinflammatory cytokines and glucocorticoids are often antagonistic. However, in some cases it can be additive or synergistic (50-52); even this synergistic effect of glucocorticoids on the production of $11 \beta$-HSD1 in the presence of proinflammatory cytokines was previously described in synovial fibroblasts (53). Our experiments in synovial cells treated with culture supernatants from B. abortus-infected monocytes in the presence of a neutralizing antibody anti-TNFRc significantly reduced $11 \beta$ HSD 1 ; however, the remaining expression of $11 \beta$-HSD 1 indicates that the contribution of other proinflammatory cytokines cannot be ruled out (Figure 8).

Finally, this is the first study that contributes to the knowledge of the effect of adrenal steroids on synoviocytes in the context of a bacterial infection. Our findings reveal that DHEA could modulate some synoviocytes function. Considering that and taking into account the modulation exerted by DHEA on other cell types in bone damage $(13,14)$, we can conclude that antibiotic therapy with supplementation with DHEA or its derivates could be a potential new treatment in order to reduce the bone damage during osteoarticular brucellosis. 


\section{DATA AVAILABILITY STATEMENT}

The datasets generated for this study are available on request to the corresponding author.

\section{AUTHOR CONTRIBUTIONS}

All authors were involved in the design of the study, the preparation of the manuscript, and approve the final version for publication. MG: conceptualization, methodology, validation, formal analysis, investigation, funding acquisition, writing review and editing. GG: conceptualization, funding acquisition, writing review and editing. MD: conceptualization, methodology, validation, formal analysis, investigation, funding acquisition-supervision, validation, visualization, and writing original draft.

\section{REFERENCES}

1. Pourbagher A, Pourbagher MA, Savas L, Turunc T, Demiroglu YZ, Erol I, et al. Epidemiologic, clinical, and imaging findings in brucellosis patients with osteoarticular involvement. AJR Am J Roentgenol. (2006) 187:873-80. doi: 10.2214/AJR.05.1088

2. Madkour MM. Osteoarticular brucellosis. In: Madkour MM, editor. Madkour's brucellosis. 2nd edn. Berlin: Springer-Verlag (2001). p. 74-84. doi: 10.1007/978-3-642-59533-2_8

3. Bosilkovski M, Krteva L, Caparoska S, Dimzova M. Osteoarticular involvement in brucellosis: study of 196 cases in the Republic of Macedonia. Croat Med J. (2004) 45:727-33.

4. Madkour MM. Bone and joint imaging. In: Madkour MM, editor. Madkour's brucellosis. 2nd edn. Berlin: Springer-Verlag (2001). p. 90-132. doi: 10.1007/978-3-642-59533-2_10

5. Gotuzzo E, Alarcon GS, Bocanegra TS, Carrillo C, Guerra JC, Rolando I, et al. Articular involvement in human brucellosis: a retrospective analysis of 304 cases. Semin Arthritis Rheum. (1982) 12:245-55. doi: 10.1016/0049-0172(82)90064-6

6. Madkour MM. Osteoarthicular brucellosis. In: Madkour MM, editor. Madkour's brucellosis. 2nd edn. Berlin: Springer-Verlag (2001). p. 150-8. doi: 10.1007/978-3-642-59533-2_13

7. Scian R, Barrionuevo P, Giambartolomei GH, De Simone EA, Vanzulli SI, Fossati CA, et al. Potential role of fibroblast-like synoviocytes in joint damage induced by Brucella abortus infection through production and induction of matrix metalloproteinases. Infect Immun. (2011) 79:3619-32. doi: 10.1128/IAI.05408-11

8. Scian R, Barrionuevo P, Rodriguez AM, Arriola Benitez PC, Garcia Samartino C, Fossati CA, et al. Brucella abortus invasion of synoviocytes inhibits apoptosis and induces bone resorption through RANKL expression. Infect Immun. (2013) 81:1940-51. doi: 10.1128/IAI.01366-12

9. Besedovsky HO, del Rey A. Immune-neuro-endocrine interactions: facts and hypotheses. Endocr Rev. (1996) 17:64-102. doi: 10.1210/edrv-17-1-64

10. McEwen BS, Biron CA, Brunson KW, Bulloch K, Chambers WH, Dhabhar FS, et al. The role of adrenocorticoids as modulators of immune function in health and disease: neural, endocrine and immune interactions. Brain Res Brain Res Rev. (1997) 23:79-133. doi: 10.1016/S0165-0173(96)00012-4

11. Loria RM. Antiglucocorticoid function of androstenetriol. Psychoneuroendocrinology. (1997) 22 (Suppl. 1):S103-8. doi: 10.1016/ S0306-4530(97)00005-X

12. Yildiz O, Gokce C, Alp E, Durak AC, Aygen B, Kelestimur F, et al. Investigation of the hypothalamo-pituitary-adrenal axis and changes in the size of adrenal glands in acute brucellosis. Endocr J. (2005) 52:183-8. doi: $10.1507 /$ endocrj.52.183

\section{FUNDING}

This work was supported by grants PICT 2014-1111 and PICT 2015-0316 from Agencia Nacional of Promoción Científica y Tecnológica (ANPCYT, Argentina), by grant PIP 2015-20170200 from Consejo Nacional de Investigaciones científicas y técnicas (CONICET). Funding agencies had no role in study design, data collection and analysis, decision to publish, or preparation of the manuscript.

\section{ACKNOWLEDGMENTS}

We thank Horacio Salomón and the staff of the Instituto de Investigaciones Biomédicas en Retrovirus y Sida (INBIRS) for their assistance with biosafety level 3 laboratory uses. MG, GG, and MD are members of the Carrera del Investigador of CONICET.

13. Gentilini MV, Velasquez LN, Barrionuevo P, Arriola Benitez PC, Giambartolomei GH, Delpino MV. Adrenal steroids modulate the immune response during Brucella abortus infection by a mechanism that depends on the regulation of cytokine production. Infect Immun. (2015) 83:1973-82. doi: 10.1128/IAI.03090-14

14. Gentilini MV, Pesce Viglietti AI, Arriola Benitez PC, Iglesias Molli $\mathrm{AE}$, Cerrone GE, Giambartolomei $\mathrm{GH}$, et al. Inhibition of osteoblast function by Brucella abortus is reversed by dehydroepiandrosterone and involves ERK1/2 and estrogen receptor. Front Immunol. (2018) 9:88. doi: 10.3389/fimmu.2018.00088

15. Hibbs MS, Hasty KA, Seyer JM, Kang AH, Mainardi CL. Biochemical and immunological characterization of the secreted forms of human neutrophil gelatinase. J Biol Chem. (1985) 260:2493-500.

16. Verbrugghe E, Boyen F, Van Parys A, Van Deun K, Croubels S, Thompson A, et al. Stress induced Salmonella Typhimurium recrudescence in pigs coincides with cortisol induced increased intracellular proliferation in macrophages. Vet Res. (2011) 42:118. doi: 10.1186/1297-9716-42-118

17. Bongiovanni B, Mata-Espinosa D, D’Attilio L, Leon-Contreras JC, MarquezVelasco R, Bottasso O, et al. Effect of cortisol and/or DHEA on THP1-derived macrophages infected with Mycobacterium tuberculosis. Tuberculosis. (2015) 95:562-9. doi: 10.1016/j.tube.2015.05.011

18. Elkington PT, O'Kane CM, Friedland JS. The paradox of matrix metalloproteinases in infectious disease. Clin Exp Immunol. (2005) 142:12-20. doi: 10.1111/j.1365-2249.2005.02840.x

19. Alsalameh S, Amin RJ, Kunisch E, Jasin HE, Kinne RW. Preferential induction of prodestructive matrix metalloproteinase-1 and proinflammatory interleukin 6 and prostaglandin E2 in rheumatoid arthritis synovial fibroblasts via tumor necrosis factor receptor-55. J Rheumatol. (2003) 30:1680-90.

20. Harris JE, Fernandez-Vilaseca M, Elkington PT, Horncastle DE, Graeber MB, Friedland JS. IFNgamma synergizes with IL-1beta to up-regulate MMP-9 secretion in a cellular model of central nervous system tuberculosis. Faseb J. (2007) 21:356-65. doi: 10.1096/fj.06-6925com

21. Nagase H, Brew K. Designing TIMP (tissue inhibitor of metalloproteinases) variants that are selective metalloproteinase inhibitors. Biochem Soc Symp. (2003) 70:201-12. doi: 10.1042/bss0700201

22. Panagakos FS, Kumar S. Modulation of proteases and their inhibitors in immortal human osteoblast-like cells by tumor necrosis factor-alpha in vitro. Inflammation. (1994) 18:243-65. doi: 10.1007/BF01534267

23. Uchida M, Shima M, Shimoaka T, Fujieda A, Obara K, Suzuki H, et al. Regulation of matrix metalloproteinases (MMPs) and tissue inhibitors of metalloproteinases (TIMPs) by bone resorptive factors in osteoblastic cells. J Cell Physiol. (2000) 185:207-14. doi: 10.1002/10974652(200011)185:2<207::AID-JCP5>3.0.CO;2-J 
24. Wright KM, Friedland JS. Regulation of monocyte chemokine and MMP-9 secretion by proinflammatory cytokines in tuberculous osteomyelitis. JLeukoc Biol. (2004) 75:1086-92. doi: 10.1189/jlb.0903433

25. Giambartolomei GH, Zwerdling A, Cassataro J, Bruno L, Fossati CA, Philipp MT. Lipoproteins, not lipopolysaccharide, are the key mediators of the proinflammatory response elicited by heat-killed Brucella abortus. J Immunol. (2004) 173:4635-42. doi: 10.4049/jimmunol.173.7.4635

26. Zhan Y, Cheers C. Differential induction of macrophage-derived cytokines by live and dead intracellular bacteria in vitro. Infect Immun. (1995) 63:720-3.

27. Delpino MV, Barrionuevo P, Macedo GC, Oliveira SC, Genaro SD, Scian R, et al. Macrophage-elicited osteoclastogenesis in response to Brucella abortus infection requires TLR2/MyD88-dependent TNF-alpha production. J Leukoc Biol. (2012) 91:285-98. doi: 10.1189/jlb.04111185

28. Miller KK, Al-Rayyan N, Ivanova MM, Mattingly KA, Ripp SL, Klinge CM, et al. DHEA metabolites activate estrogen receptors alpha and beta. Steroids. (2013) 78:15-25. doi: 10.1016/j.steroids.2012.10.002

29. Huang Y, Liu L, Liu A. Dickkopf-1: current knowledge and related diseases. Life Sci. (2018) 209:249-54. doi: 10.1016/j.lfs.2018.08.019

30. Hardy R, Cooper MS. Adrenal gland and bone. Arch Biochem Biophys. (2010) 503:137-45. doi: 10.1016/j.abb.2010.06.007

31. Thieringer R, Le Grand CB, Carbin L, Cai TQ, Wong B, Wright SD, et al. 11 Beta-hydroxysteroid dehydrogenase type 1 is induced in human monocytes upon differentiation to macrophages. J Immunol. (2001) 167:30-5. doi: 10.4049/jimmunol.167.1.30

32. Oakley RH, Cidlowski JA. Cellular processing of the glucocorticoid receptor gene and protein: new mechanisms for generating tissuespecific actions of glucocorticoids. J Biol Chem. (2011) 286:3177-84. doi: 10.1074/jbc.R110.179325

33. Zhang YH, Heulsmann A, Tondravi MM, Mukherjee A, Abu-Amer Y. Tumor necrosis factor-alpha (TNF) stimulates RANKL-induced osteoclastogenesis via coupling of TNF type 1 receptor and RANK signaling pathways. J Biol Chem. (2001) 276:563-8. doi: 10.1074/jbc.M008198200

34. Heiniger CD, Rochat MK, Frey FJ, Frey BM. TNF-alpha enhances intracellular glucocorticoid availability. FEBS Lett. (2001) 507:351-6. doi: 10.1016/S0014-5793(01)03004-6

35. Sacco M, Valenti G, Corvi Mora P, Wu FC, Ray DW. DHEA, a selective glucocorticoid receptor antagonist: its role in immune system regulation and metabolism. J Endocrinol Invest. (2002) 25(10 Suppl.):81-2.

36. Oneal MJ, Schafer ER, Madsen ML, Minion FC. Global transcriptional analysis of Mycoplasma hyopneumoniae following exposure to norepinephrine. Microbiology. (2008) 154(Pt 9):2581-8. doi: 10.1099/mic.0.2008/020230-0

37. Nakano M, Takahashi A, Sakai Y, Nakaya Y. Modulation of pathogenicity with norepinephrine related to the type III secretion system of Vibrio parahaemolyticus. J Infect Dis. (2007) 195:1353-60. doi: 10.1086/513275

38. Banerjee D, Martin N, Nandi S, Shukla S, Dominguez A, Mukhopadhyay $\mathrm{G}$, et al. A genome-wide steroid response study of the major human fungal pathogen Candida albicans. Mycopathologia. (2007) 164:1-17. doi: 10.1007/s11046-007-9025-8

39. Miyazawa K, Mori A, Okudaira H. Regulation of interleukin-1betainduced interleukin-6 gene expression in human fibroblast-like synoviocytes by glucocorticoids. J Biochem. (1998) 124:1130-7. doi: 10.1093/oxfordjournals.jbchem.a022231

40. Takayanagi H, Iizuka H, Juji T, Nakagawa T, Yamamoto A, Miyazaki $\mathrm{T}$, et al. Involvement of receptor activator of nuclear factor kappaB ligand/osteoclast differentiation factor in osteoclastogenesis from synoviocytes in rheumatoid arthritis. Arthritis Rheum. (2000) 43:259-69. doi: 10.1002/1529-0131(200002)43:2<259::AID-ANR4>3.0.CO;2-W

41. Wang YD, Wang L, Li DJ, Wang WJ. Dehydroepiandrosterone inhibited the bone resorption through the upregulation of OPG/RANKL. Cell Mol Immunol. (2006) 3:41-5.
42. Harding G, Mak YT, Evans B, Cheung J, MacDonald D, Hampson G. The effects of dexamethasone and dehydroepiandrosterone (DHEA) on cytokines and receptor expression in a human osteoblastic cell line: potential steroid-sparing role for DHEA. Cytokine. (2006) 36(1-2):57-68. doi: 10.1016/j.cyto.2006.10.012

43. Engdahl C, Lagerquist MK, Stubelius A, Andersson A, Studer E, Ohlsson $\mathrm{C}$, et al. Role of androgen and estrogen receptors for the action of dehydroepiandrosterone (DHEA). Endocrinology. (2014) 155:889-96. doi: 10.1210/en.2013-1561

44. Wang YD, Tao MF, Wang L, Cheng WW, Wan XP. Selective regulation of osteoblastic OPG and RANKL by dehydroepiandrosterone through activation of the estrogen receptor beta-mediated MAPK signaling pathway. Horm Metab Res. (2012) 44:494-500. doi: 10.1055/s-00321311567

45. Cutolo M, Straub RH, Bijlsma JW. Neuroendocrine-immune interactions in synovitis. Nat Clin Pract Rheumatol. (2007) 3:627-34. doi: 10.1038/ncprheum0601

46. Diarra D, Stolina M, Polzer K, Zwerina J, Ominsky MS, Dwyer D, et al. Dickkopf-1 is a master regulator of joint remodeling. Nat Med. (2007) 13:15663. doi: $10.1038 / \mathrm{nm} 1538$

47. Yeremenko N, Zwerina K, Rigter G, Pots D, Fonseca JE, Zwerina J, et al. Tumor necrosis factor and interleukin-6 differentially regulate Dkk1 in the inflamed arthritic joint. Arthritis Rheumatol. (2015) 67:2071-5. doi: 10.1002/art.39183

48. Yoshida Y, Yamasaki S, Oi K, Kuranobu T, Nojima T, Miyaki S, et al. IL-1beta Enhances Wnt Signal by Inhibiting DKK1. Inflammation. (2018) 41:1945-54. doi: 10.1007/s10753-018-0838-z

49. Freeman L, Hewison M, Hughes SV, Evans KN, Hardie D, Means TK, et al. Expression of 11beta-hydroxysteroid dehydrogenase type 1 permits regulation of glucocorticoid bioavailability by human dendritic cells. Blood. (2005) 106:2042-9. doi: 10.1182/blood-2005-01-0186

50. Hermoso MA, Matsuguchi T, Smoak K, Cidlowski JA. Glucocorticoids and tumor necrosis factor alpha cooperatively regulate toll-like receptor 2 gene expression. Mol Cell Biol. (2004) 24:4743-56. doi: 10.1128/MCB.24.11.4743-4756.2004

51. Trujillo ME, Lee MJ, Sullivan S, Feng J, Schneider SH, Greenberg AS, et al. Tumor necrosis factor alpha and glucocorticoid synergistically increase leptin production in human adipose tissue: role for p38 mitogen-activated protein kinase. J Clin Endocrinol Metab. (2006) 91:1484-90. doi: 10.1210/jc.20051901

52. Homma T, Kato A, Hashimoto N, Batchelor J, Yoshikawa M, Imai S, et al. Corticosteroid and cytokines synergistically enhance toll-like receptor 2 expression in respiratory epithelial cells. Am J Respir Cell Mol Biol. (2004) 31:463-9. doi: 10.1165/rcmb.2004-0161OC

53. Kaur K, Hardy R, Ahasan MM, Eijken M, van Leeuwen JP, Filer A, et al. Synergistic induction of local glucocorticoid generation by inflammatory cytokines and glucocorticoids: implications for inflammation associated bone loss. Ann Rheum Dis. (2009) 69:1185-90. doi: 10.1136/ard.2009. 107466

Conflict of Interest: The authors declare that the research was conducted in the absence of any commercial or financial relationships that could be construed as a potential conflict of interest.

Copyright (c) 2019 Gentilini, Giambartolomei and Delpino. This is an open-access article distributed under the terms of the Creative Commons Attribution License (CC $B Y)$. The use, distribution or reproduction in other forums is permitted, provided the original author(s) and the copyright owner(s) are credited and that the original publication in this journal is cited, in accordance with accepted academic practice. No use, distribution or reproduction is permitted which does not comply with these terms. 